\title{
Environmental effects on flowering characteristics and kernel set of maize (Zea mays L.)
}

\author{
P. C. Struik ${ }^{1}$, M. Doorgeest ${ }^{1}$ and J. G. Boonman ${ }^{2}$
}

${ }^{1}$ Department of Field Crops and Grassland Science, Agricultural University, P.O. Box 9101, 6709 RZ Wageningen, Netherlands

${ }^{2}$ Zelder B.V., P.O. Box 26, 6590 AA Gennep, Netherlands

Received 7 May 1986; accepted 10 July 1986

Key words: anthesis, silking, pollination, pollen shedding-silking interval, kernel set, temperature, heat stress, drought, photoperiod, genotype

\section{Summary}

In a phytotron experiment, two hybrids of maize (Zea mays L.) were exposed to different levels of temperature, heat around noon, photoperiod and water supply at certain stages of development. Treatments influenced the flowering biology, whereas they could hardly affect the leaf number.

High temperature from tassel initiation until grain set increased the rate of development, but shortened the duration of pollen shedding; the interval between pollen shedding and silking was much longer. Thus the exposure of silks to pollen was curtailed. Kernel set in the uppermost ear was hampered.

The effect of extra heat from tassel emergence until grain set was minor.

Long days from tassel initiation to tassel emergence delayed silking more than anthesis, thus increasing the desynchronization. Long photoperiod shortened the duration of the pollination period, but it increased the number of female spikelets and the number of kernels.

Drought from tassel emergence until grain set delayed anthesis by 1-2 days and silking by 4 days. Drought did not consistently reduce the duration of pollen shedding, but it impeded grain set. Many interactions between environmental factors and/or hybrid proved to be significant.

Variation in number of female florets was partly explained by desynchronization of inflorescences. There was a highly significant $\left(r^{2}=0.64 ; n=32\right)$ simple, positive correlation between relative grain set and duration of the period of pollination of the silks by the plant's own pollen. The scatter around this relationship was mainly due to the effects of water availability on the functionality of male and female florets.

The final number of kernels correlated closely with the desynchronization, although this relationship depended on hybrid and photoperiod.

The environmental effects that influence flowering of maize are summarized in a simplified model of the dynamics of anthesis and silking. 


\section{Introduction}

Maize (Zea mays L.) is a monoecious plant with the staminate inflorescence (the 'tassel') on top of the main stem and with one or more pistillate inflorescences (the 'ears') on top of lateral branches in the axils of the large leaves in the mid-section of the stem.

Under normal climatic conditions and for adapted genotypes, the ears are initiated a few days after tassel initiation (Fuchs, 1968; Hollinger, 1981). If, during its early development, the ear lags behind the tassel more than normal, the gap between male and female flowering can widen greatly (Struik, 1982;1983a). It is commonly believed that the tassel sheds its first pollen ('anthesis') some time before the first styles of the pistils (silks) extrude from the uppermost ears ('silking'). This phenomenon is known as protandry. However, protogyny (i.e. silking starts before anthesis) has also been observed, mainly when photoperiod is short, light intensity is high and (especially) temperature is moderate (e.g. Struik, 1982; 1983a, b, c). Protogyny occurs frequently under field conditions in northwest Europe because the average temperatures are low and the adapted genotypes are fairly day neutral.

The time lag between the start of silking $(q)$ and the start of pollen shedding $\left(\sigma^{\prime}\right)$ will be called 'desynchronization'. In the equation $Q-\sigma^{\prime}$, desynchronization is given a plus sign in the case of protandry and a minus sign when protogyny occurs. Desynchronization is not only affected by environmental factors but also depends on genotype (Buren et al., 1974; Bertin et al., 1976).

A large desynchronization is undesirable: it means that less pollen is available during the extrusion of the silks that arise from the florets on top of the uppermost ear or those that arise from the lower ears. Desynchronization reflects the organ interactions between tassel and ears. The tassel competes with developing ears for nutrients and photosynthates (Duncan et al., 1967) and possibly also for plant hormones. A strong apical dominance of the tassel is undesirable, because it promotes desynchronization and because it delays and retards the growth of the ear (Muleba et al., 1983). Apical dominance is reinforced by environmental stress (Phillips, 1975). Struik (1983d) also suggested that genotypes showing a large desynchronization are more sensitive to environmental stresses. According to Buren et al. (1974) small tassel size is indeed associated with tolerance to high plant density.

It would be interesting to know whether environmental stress can impede grain set by inducing such a long desynchronization that no silks will be pollinated at all. Grain set is determined by:

- the duration of the period that functional silks are exposed to viable pollen (cf. Sadras et al., 1985a, b). This duration depends on the dynamics of pollen shedding per tassel and of silk extrusion per ear, the plant-to-plant variation in date of anthesis and of silking, the numbers of pollen grains and of female spikelets, pollen characteristics (e.g. viability) and characteristics of female spikelets (e.g. viability, time and duration of receptiveness of silks).

- success of pollination and fertilization.

- abortion of kernels (cf. Struik \& Deinum, 1982; Struik, 1983b, c).

The dynamics of pollen shedding, silk emergence, fertilization and grain set have 
been described by Hall et al. (1982) and by Sadras et al. (1985a, b). They found that pollen production was skewed towards the beginning of pollen shedding. All silks had emerged on the fourth day after the start of silk extrusion. Kernel set reached its maximum on day 4. Tollenaar \& Daynard (1978a) found that tip florets were fertilized 3-5 days later than basal florets. Struik (unpublished data), however, observed that in the Netherlands seven days of pollination were required for maximum kernel set in the uppermost ear.

The dynamics of pollen shedding and silk emergence are influenced by temperature (including cold spells and heat), photoperiod, drought, light intensity, etc. Silking tends to be delayed more than anthesis when plants are stressed (Hall et al., 1980; Herrero \& Johnson, 1981; Hall et al., 1982; Kiniry \& Keener, 1982; Struik, 1983d; Dow et al., 1984; Sadras et al., 1985a, b). Thus stress increases desynchronization and reduces possibilities for pollination.

Pollen viability, number of pollen grains and rate of pollen production are reduced by heat (e.g. Herrero \& Johnson, 1980) and drought (e.g. Sadras et al., 1985b). Drought might also impede anther extrusion (Hall et al., 1982). Extrusion and elongation rate of silks are reduced by drought (Herrero \& Johnson, 1981), whereas drought also reduces the final number of silks by halting the initiation of florets at an earlier stage (Hollinger, 1981). Drought also causes abortion of the embryo sac (Moss \& Downey, 1971). Silks stay receptive for at least 6 days, and a minimum of 5 pollen grains are needed per silk to ensure $90 \%$ pollination (Sadras et al., 1985a).

Abortion of pollinated florets and kernels is poorly understood but is certainly affected by water stress (e.g. Moss \& Downey, 1971; Herrero \& Johnson, 1981), temperature (Struik, 1983b), light intensity (Struik \& Deinum, 1982; Struik, 1983b, c), heat (Schoper et al., 1985) and other factors such as defoliation (Tollenaar \& Daynard, 1978b).

The purpose of this paper is to illustrate the importance of certain climatic factors and their interactions for co-ordinating the availability of pollen and silks and thus for the possibilities for pollination and fertilization. These effects will be related to the observed numbers of kernels set.

\section{Materials and methods}

Two common European varieties, LG 11 and Bastion, were grown in growth chambers with a net area of approximately $10 \mathrm{~m}^{2}$. Photosynthetically active radiation was $100-120 \mathrm{~W} \mathrm{~m}^{-2}(400-700 \mathrm{~nm}) 1.20 \mathrm{~m}$ above the floor for $12 \mathrm{~h}$. Long-day treatments $(24 \mathrm{~h})$ were achieved by four incandescent lamps $(100 \mathrm{~W})$ over $10 \mathrm{~m}^{2}$. Relative humidity was maintained at $75 \%$ until tassel emergence: thereafter it was maintained at $40 \%$. The volume fraction of $\mathrm{CO}_{2}$ in air was $450 \times 10^{-6}$.

For each variety, four seeds were sown per plastic pot. The pots contained 10 litres of a mixture of sandy soil and peat in equal volumes. The number of seedlings was reduced to one per pot after emergence. Final plant density was about $6 \mathrm{~m}^{-2}$. Nutrient solution was provided adequately. Plants were watered once a day, except 
in the drought treatments. Weed, pest and disease control were carried out when necessary.

The experiment was carried out as a randomized split-plot design with 8 replications and 32 plants within each replication (i.e. 16 plants of each genotype). Each of these 16 plants was exposed to a different series of environmental conditions (Table 1$)$. Both varieties were exposed to a day $(12 \mathrm{~h}) /$ night $(12 \mathrm{~h})$ temperature of $18 / 12{ }^{\circ} \mathrm{C}$ during germination and early growth. Tassel initiation was ascertained by dissecting spare plants. It occurred in the 6-leaf stage for both varieties. From that stage until tassel emergence plants were exposed to four different climates by varying both air temperature (low temperature $=\mathrm{LT}=18 / 12^{\circ} \mathrm{C}$ or high temperature $=$ $\mathrm{HT}=30 / 24^{\circ} \mathrm{C}$ ) and photoperiod (short photoperiod $=\mathrm{SP}=12 \mathrm{~h}$ basic light, or long photoperiod $=\mathrm{LP}=12 \mathrm{~h}$ basic light $+12 \mathrm{~h}$ photoperiod extension). By starting these treatments after tassel initiation, large effects on the number of leaves initiated were avoided. The efficacy of a long-day treatment declines, the longer its start is delayed (Struik, 1982). Therefore it was surmised that this treatment could be stopped at tassel emergence without reducing the effects.

At tassel emergence two other treatments were started. Temperature during the noon period (i.e. the 6 - $\mathrm{h}$ period from $3 \mathrm{~h}$ after the onset of the basic light until $3 \mathrm{~h}$ before the end of the basic light period) was kept at the normal day temperature level (low noon temperature $=\mathrm{LNT}=18$ or $30^{\circ} \mathrm{C}$ ) or was $6^{\circ} \mathrm{C}$ higher than the normal day temperature (high noon temperature $=\mathrm{HNT}=24$ or $36^{\circ} \mathrm{C}$ ). Water supply was varied by providing half of the plants with abundant water (AW) and by giving the other plants a restricted amount (RW) when plants were observed to be wilting seriously. This restricted amount was $40 \%(\mathrm{HT})$ or $32 \%(\mathrm{LT})$ of abundant water

Table 1. Schedule of the treatments. Codes are given in parentheses.

\begin{tabular}{|c|c|c|c|}
\hline \multirow[t]{2}{*}{ Factor } & \multicolumn{3}{|c|}{ Physiological stage } \\
\hline & $\begin{array}{l}\text { sowing- } \\
\text { tassel initiation }\end{array}$ & $\begin{array}{l}\text { tassel initiation- } \\
\text { tassel emergence }\end{array}$ & $\begin{array}{l}\text { tassel emergence- } \\
\text { grain set }\end{array}$ \\
\hline \multirow[t]{2}{*}{ Hybrid (H) } & LG 11 & LG 11 & LG 11 \\
\hline & Bastion & Bastion & Bastion \\
\hline \multirow[t]{2}{*}{ Day/night temperature $(\mathrm{T})$ in ${ }^{\circ} \mathrm{C}$} & $18 / 12$ & $18 / 12(\mathrm{LT})$ & 18/12 (LT) \\
\hline & & $30 / 24(\mathrm{HT})$ & $30 / 24(\mathrm{HT})$ \\
\hline \multirow[t]{2}{*}{ Noon temperature (NT) in ${ }^{\circ} \mathrm{C}$} & 18 & 18 or 30 & 18 or $30(\mathrm{LNT})$ \\
\hline & & & 24 or $36(\mathrm{HNT})$ \\
\hline \multirow[t]{2}{*}{ Photoperiod $(\mathrm{P})$ in $\mathrm{h}$} & 12 & $12(\mathrm{SP})$ & 12 \\
\hline & & $24(\mathrm{LP})$ & \\
\hline Relative humidity in $\%$ & 75 & 75 & 40 \\
\hline Water supply (W) & abundant & abundant & $\begin{array}{l}\text { abundant }(\mathrm{AW})^{*} \\
\text { restricted }(\mathrm{RW})^{* *}\end{array}$ \\
\hline Number of treatments during stage & $2^{1}$ & $2^{3}$ & $2^{4}$ \\
\hline Total number of treatments & 2 & 8 & 32 \\
\hline
\end{tabular}

* $0.56 \mathrm{l}$ per plant per day at $\mathrm{HT}$ and $0.42 \mathrm{l}$ per plant per day at $\mathrm{LT}$, on an average.

** 0.231 per plant per day at $\mathrm{HT}$ and $0.13 \mathrm{I}$ per plant per day at $\mathrm{LT}$, on an average. 

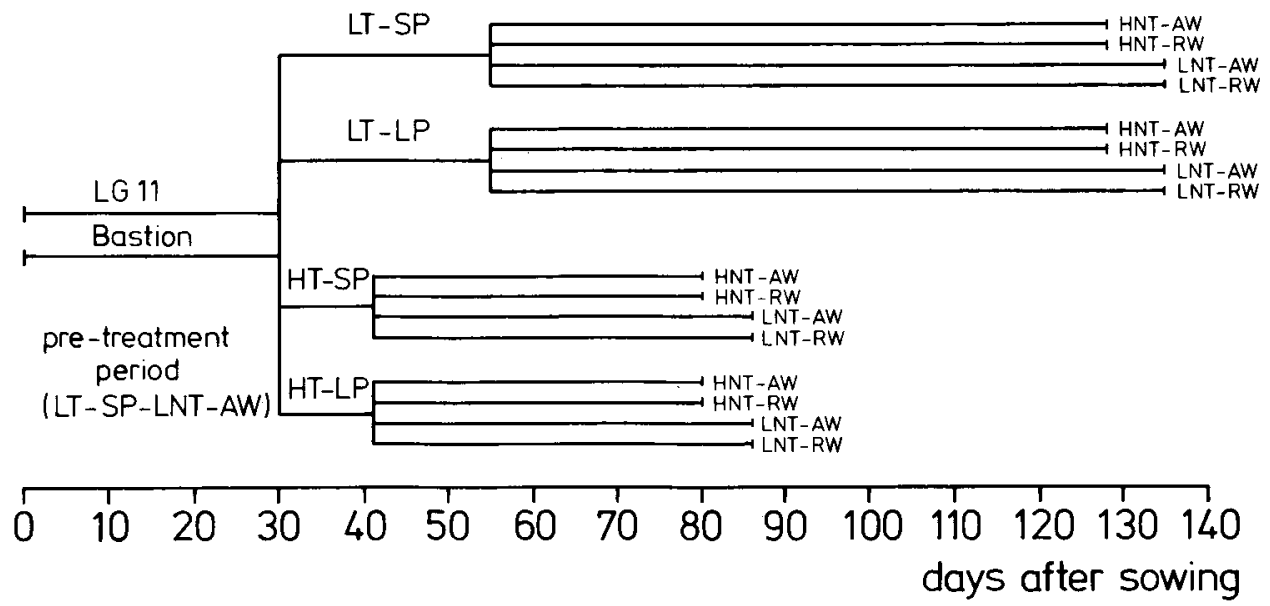

Fig. 1. Time-table for the environmental conditions to which plants of the hybrids LG 11 and Bastion were exposed. For treatment codes see Table 1.

supply. In order to increase the effectiveness of the water-stress treatment the relative humidity was lowered to $40 \%$. In the field, heat, high temperature and water stress frequently occur. The long-day treatment was included to enlarge possible effects of the other climatic factors (cf. Struik, 1982). A time-table is presented in Fig. 1.

Maximum area of each leaf was calculated as maximum length $\times$ maximum width $\times 0.75$ (Montgomery, 1911). Dates of the first ('start of anthesis') and last visible pollen shedding ('end of anthesis') and first visible silk extrusion ('silking') were recorded for each plant separately. These data were expressed in days after sowing. Plants were checked daily at the same time of day. All the ears were hand-pollinated daily with pollen taken from the tassel of the same stem that bore these ears, as far as and for as long as pollen was available. The ears were covered with paper bags to prevent cross-pollination. The visible female florets ('potential kernel number') and the kernels that showed active dry-matter accumulation ('actual kernel number') were counted at harvest. It proved difficult to count female florets, especially in the high-temperature treatments. Tassel length (measured from the axil of the top leaf) and the number of tassel branches were estimated some time after anthesis. During silking and at final harvest abnormalities in ear development were also recorded.

From the recorded data the following parameters were calculated:

- the duration of the period of pollen shedding ('duration of anthesis'), i.e. the last day of pollen shedding minus the first day of pollen shedding

- the desynchronization, i.e. the first day of silk emergence minus the first day of pollen shedding

- the hypothetical duration of pollination, i.e. the last day of pollen shedding minus 
the first day of silk emergence or the duration of anthesis minus the desynchronization

- the true duration of pollination, i.e. the duration of exposure of silks to pollen. The true duration of pollination is equal to the hypothetical duration if the desynchronization is $\geqslant 0$ and the plant starts to silk before the end of anthesis

- the relative grain set, i.e. the actual kernel number divided by the potential kernel number, times $100 \%$.

Dry-matter yields are of little relevance in phytotron experiments, where plant height and leaf area are affected by treatments. Although yields were recorded they will not be mentioned in this paper.

Data were analysed with standard procedures for analysis of variance (SPSS MANOVA). All tabulated parameters were checked for normality. Parameters related to silking date all showed significant skewness and kurtosis. Simple transformations could not solve this problem.

\section{Results}

As expected, the final number of leaves was only slightly affected by genotype or climatic conditions. The final number of leaves was 0.5 leaves per plant lower for Bastion than for LG 11. High temperature caused a significant increase in leaf number ( 0.5 leaves/plant).

This small effect indicates that not all plants had reached the tassel-initiation stage at the end of the pre-treatment period. Yet, photoperiod did not affect leaf number, and no interaction was found between genotype and temperature. The rate of growth was not affected by photoperiod and therefore all plants within one temperature treatment could be simultaneously transferred to the new conditions after tassel emergence.

\section{Main effects on floral biology}

Table 2 gives the data on the floral biology of the plants, averaged over all factors but one. Table 3 gives the results of the analysis of variance. Pollen shedding started 1 day earlier for Bastion than for LG 11, but ended 2 days earlier, resulting in a shorter duration of pollen shedding. This was surprising, because Bastion produced many more primary tassel branches than LG 11 (average per plant 17.9 versus 11.4). We also observed that Bastion showed a considerable time lag between the extrusion of the first anthers and the shedding of the first pollen, especially at drought and low temperature.

Low temperature delayed both the start and the end of anthesis and resulted in a considerably longer period of pollen shedding. Anthesis was somewhat delayed by a higher noon temperature. Long days after tassel initiation postponed anthesis but lengthened the period of pollen shedding. Restricted water supply also delayed anthesis but did not consistently affect the duration of pollen shedding.

We did not record the number of pollen grains shed per day. Based on the number of tassel branches, the length and dry weight of the tassel, and general observations on tassel appearance, however, we can state that 
Table 2. Main effects of the different treatments on floral biology and kernel set (weighted average of 128 plants).

\begin{tabular}{|c|c|c|c|c|c|c|c|c|c|c|}
\hline \multirow{2}{*}{$\begin{array}{l}\qquad \text { Factor } \rightarrow \\
\text { Parameter } \\
\downarrow\end{array}$} & \multicolumn{2}{|l|}{ Hybrid } & \multicolumn{2}{|c|}{ Temperature } & \multicolumn{2}{|c|}{ Noon temperature } & \multicolumn{2}{|c|}{ Photoperiod } & \multicolumn{2}{|c|}{ Water supply } \\
\hline & LG 11 & Bastion & low & high & low & high & $12 \mathrm{~h}$ & $24 \mathrm{~h}$ & ample & restricted \\
\hline Anthesis start ${ }^{\mathrm{a}}$ & 66.7 & 65.3 & 76.4 & 55.6 & 65.8 & 66.3 & 64.7 & 67.3 & 65.3 & 66.8 \\
\hline end ${ }^{a}$ & 75.5 & 73.2 & 86.1 & 62.6 & 74.1 & 74.6 & 72.6 & 76.1 & 73.4 & 75.3 \\
\hline duration $^{b}$ & 8.9 & 7.8 & 9.7 & 7.0 & 8.3 & 8.4 & 7.8 & 8.9 & 8.1 & 8.6 \\
\hline Silking ${ }^{\mathrm{a}}$ & 69.7 & 67.3 & 75.8 & 61.1 & 68.7 & 68.2 & 64.9 & 72.1 & 66.4 & 70.6 \\
\hline Desynchronization $^{\mathrm{b}}$ & 3.0 & 2.0 & -0.5 & 5.5 & 3.0 & 2.0 & 0.1 & 4.8 & 1.1 & 3.8 \\
\hline \multicolumn{11}{|l|}{ Duration of pollination } \\
\hline hypothetical ${ }^{\mathrm{b}}$ & 5.8 & 5.9 & 10.2 & 1.5 & 5.4 & 6.4 & 7.7 & 4.0 & 7.0 & 4.8 \\
\hline true $^{\mathrm{b}}$ & 7.3 & 6.0 & 10.2 & 3.0 & 6.3 & 6.9 & 7.9 & 5.3 & 7.4 & 5.8 \\
\hline \multicolumn{11}{|l|}{ Kernel number } \\
\hline potential & 363 & 363 & 395 & 332 & 354 & 372 & 333 & 393 & 378 & 349 \\
\hline actual & 171 & 190 & 294 & 70 & 178 & 183 & 161 & 200 & 225 & 135 \\
\hline
\end{tabular}

${ }^{a}$ days after sowing; ${ }^{b}$ days.

- Bastion shed more pollen per day than LG 11

- plants grown under low temperature shed more pollen than plants grown under high temperatures.

From these observations it may be concluded that only at high temperatures could the availability of pollen per se be a limiting factor for grain set.

The effects of genotype and climatic conditions on the date of the first extrusion of silks were similar to those observed for pollen shed (Table 2). However, ear development proved to be more sensitive to environmental stresses than tassel development. This is illustrated by the desynchronization. High temperature, long photoperiod and water shortage increased desynchronization considerably, whereas their effects on duration of anthesis were fairly small. High noon temperature significantly reduced desynchronization. Protogyny was observed very frequently at low temperature. The period during which new silks were extruded could last many days. At high temperature only a few silks extruded per day, especially in wilting plants. Since the pollen shed is skewed towards the start of the anthesis, desynchronization might be a limiting factor for grain set at high temperature or under drought stress. In some treatments (e.g. for LG 11 at high temperature and restricted water) desynchronization was extremely large.

To evaluate the possibilities for pollination we calculated the hypothetical duration and the true duration of pollination (Table 2). Hypothetical duration is statistically more manageable. True duration is more relevant for kernel set. Differences between these two parameters are caused by protogyny (when silks are available but pollen is not) and by extreme desynchronization (when first silks are extruding after the last pollen has been shed: this only occurred for LG 11). If pollination was possible, then the pollination period lasted longer for LG 11 than for Bastion. Pollination was also prolonged by lower temperature, high noon temperature, short photoperiod and abundant water. 
Table 3. Significance of the main effects of hybrid $(H)$, temperature $(T)$, noon temperature $(N T)$, photoperiod (P) and water supply (W) and the significance of all possible interactions for all parameters given in Table 2.



These data indicate that high temperature, long days and drought limited the availability of pollen during the period that receptive silks were available. Temperature was the most crucial factor.

The potential number of kernels, i.e. total number of visible spikelets (aborted or 
not) was increased by long days, but reduced by high temperature and drought. Genotype and noon temperature did not affect the number of spikelets. The main effects were fairly small, but individual combinations of factors differed considerably.

Differences in floral biology were translated into differences in number of kernels (Table 2). High temperature and restricted water supply reduced the number of kernels. In contrast, long days significantly increased kernel number, even though they shortened the pollination period by increasing desynchronization.

\section{Interactions}

Many interactions between climatic factors and/or genotype proved to be significant (Table 3). Some of these are too complicated to be interpretable. However, all significant four-factor and five-factor interactions were significant at the 0.05 or 0.10 level only.

The most important and frequently occurring two-factor interactions were $\mathrm{H} \times$ $\mathrm{T}, \mathrm{T} \times \mathrm{P}$ and $\mathrm{T} \times \mathrm{W}$. Some three-factor interactions between $\mathrm{H}, \mathrm{T}, \mathrm{P}$ or $\mathrm{W}$ were also often significant: $\mathrm{H} \times \mathrm{T} \times \mathrm{P}, \mathrm{H} \times \mathrm{T} \times \mathrm{W}$ and $\mathrm{T} \times \mathrm{P} \times \mathrm{W}$. There were no general trends: for example, for some parameters LG 11 reacted more severely to an environmental factor, whereas for other parameters Bastion reacted more to the same stress. This clearly shows the complexity of the phenology of maize.

Some parameters more often showed significant interactions than others. Many significant interactions were, for example, found for last day of pollen shedding, for true duration of pollination, and for potential and actual kernel numbers. A surprising interaction between temperature and water availability was observed for the duration of anthesis of Bastion: drought dramatically curtailed the duration at low temperature whereas it lengthened the duration at high temperature. For Bastion, anthesis lasted particularly long for the treatments LNT-LT-LP-AW and HNT-LTLP-AW. Therefore, the pollination period lasted long, although the desynchronization in the treatments was three days in both cases.

\section{Relevant relationships between parameters observed}

Desynchronization and duration of pollination are the most useful parameters for interpreting the interactions between inflorescences, the relevance of these interactions for number of kernels, and the main effects of environmental factors on these interactions.

Desynchronization is probably the best indicator of the apical dominance of the tassel over the ear. If this dominance is high, ear development is delayed, although many spikelets may ultimately be initiated. If this dominance is small, the rate of ear development might be so high that there is insufficient time to produce many female spikelets. Fig. 2 shows the relationship between desynchronization and number of female spikelets. At low temperature the dominance is low (e.g. resulting in pronounced protogyny). This smaller dominance is also illustrated by the observation that there were fewer internodes above the uppermost ear at low temperature than at high temperature, whereas there were more silking ears at low temperature. In this case, slowing down the ear development (e.g. by LP) had a positive effect on number of spikelets. Large desynchronization at high temperatures, howev- 


$$
\begin{aligned}
& \text { LT : } y=16.84 x+404.37 ; r^{2}=0.576^{* * *}(n=16) \\
& \text { HT : } y=-8.74 x+379.92 ; r^{2}=0.519^{* *}(n=16) \\
& \text { SP: } y=-1.61 x+333.60 ; r^{2}=0.031^{n s} \quad(n=16) \\
& \text { LP: } y=-14.51 x+463.86 ; r^{2}=0.573^{* * *}(n=16)
\end{aligned}
$$

number of spikelets per uppermost ear

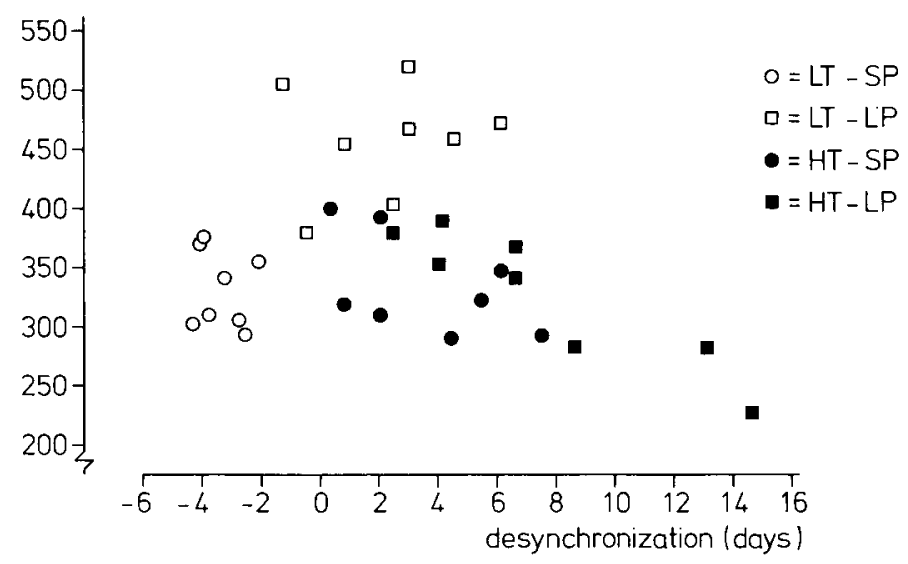

Fig. 2. The relationship between desynchronization and number of spikelets per uppermost ear of plants of two hybrids, exposed to different climatic conditions (each point represents the average of 8 plants). (It was difficult to estimate number of spikelets, especially of ears developed at high temperature.)

er, was associated with small ears, bearing few spikelets. The relationship shown in Fig. 2 fits in nicely with the data from Exp. 2 of Struik (1982).

The duration of pollination appeared to explain two-thirds of the variation in relative grain set (Fig. 3). For LG 11 alone, more than $80 \%$ of the variation could be explained. Much of the scatter at prolonged pollination can be attributed to differences in availability of water: at low temperature, drought moderately affected the duration of the pollination period but severely reduced relative grain set, especially for LG 11. For Bastion, relative grain set was reduced and pollination was shortened when drought was combined with long days and low temperature. Nevertheless, it is clearly shown that the duration of the period that silks are exposed to pollen is an important factor in determining the number of grains. In addition to duration of the pollination period, the functionality of silks and of pollen, and the abortion of florets and kernels are also relevant.

There was a close semi-log relationship $\left(r^{2}=0.931 ; P<0.001 ; n=22\right)$ between duration of the pollination period and desynchronization for the HT treatments of LG 11 and Bastion and for most of the LT treatments of Bastion. For the LT treatments of LG 11 plus the Bastion treatments LNT-LT-LP-AW and HNT-LT-LP$\mathrm{AW}$, the relationship was a straight line $\left(r^{2}=0.918 ; P<0.001 ; n=10\right)$. For these 


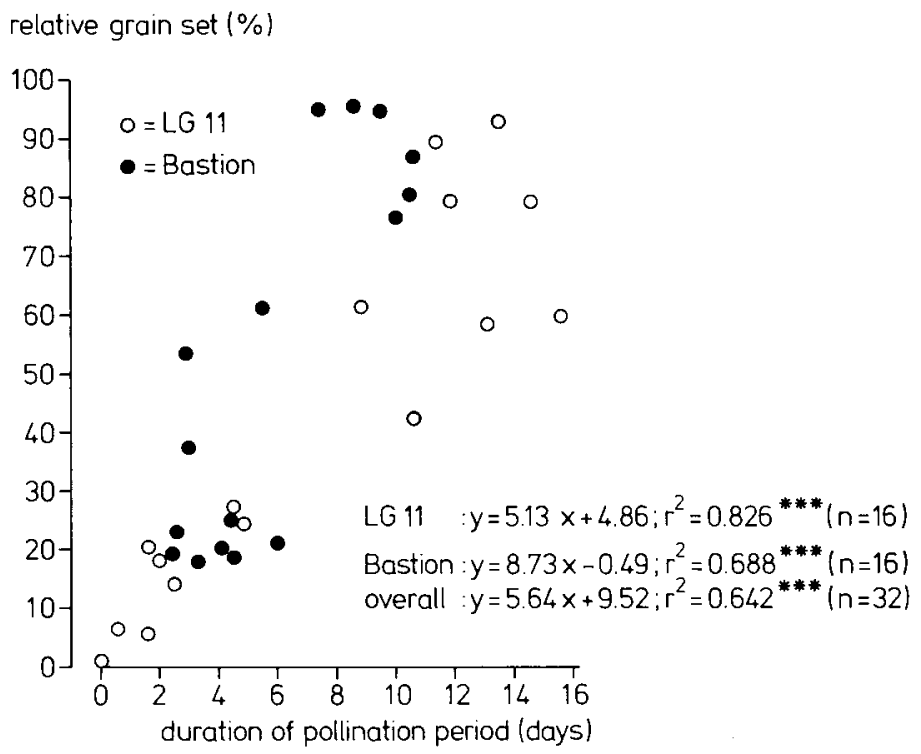

Fig. 3. The relationship between true duration of the pollination period and relative grain set of plants of LG 11 (open symbols) and Bastion (black symbols) exposed to different climatic conditions (average of 8 plants).

10 treatments pollination lasted about 4 days longer at the same desynchronization than for the other 22 treatments. This increase in fecundity was associated with a high number of primary tassel branches at low temperature for LG 11. The aberration of the two Bastion treatments was discussed above.

Fig. 4 shows the relationship between desynchronization and relative grain set. The success of pollination depended on the presence of functional silks during the availability of pollen. However, the increase in desynchronization caused by long days hardly reduced the success of pollination. This suggests that pollination lasted much longer than necessary at short days and low temperature.

At low temperature, long days stimulated the initiation of female spikelets without greatly reducing their chance of being fertilized thus increasing the number of kernels (Fig. 5). Much of the variation in kernel number can be explained by variation in desynchronization if separate regression lines are calculated for long and short photoperiods. The curve for short photoperiod lies below the curve for long photoperiod. At short days LG 11 and Bastion fitted in with the same curve. At long days most of the scatter occurred in Bastion, mainly because of the treatments LNT-LT-LP-AW and HNT-LT-LP-AW, where the desynchronization was much higher than could be expected from the duration of pollination (see above).

No loss of functionality of silks was observed, not even when protogyny lasted more than 4 days. 


$$
\begin{aligned}
& S P: y=-29.34 \ln (x+5)+85.95 ; r^{2}=0.776^{* * *}(n=16) \\
& L P: y=-50.75 \ln (x+5)+156.57 ; r^{2}=0.493^{* *}(n=16)
\end{aligned}
$$

relative grain set in uppermost ear $(\%)$

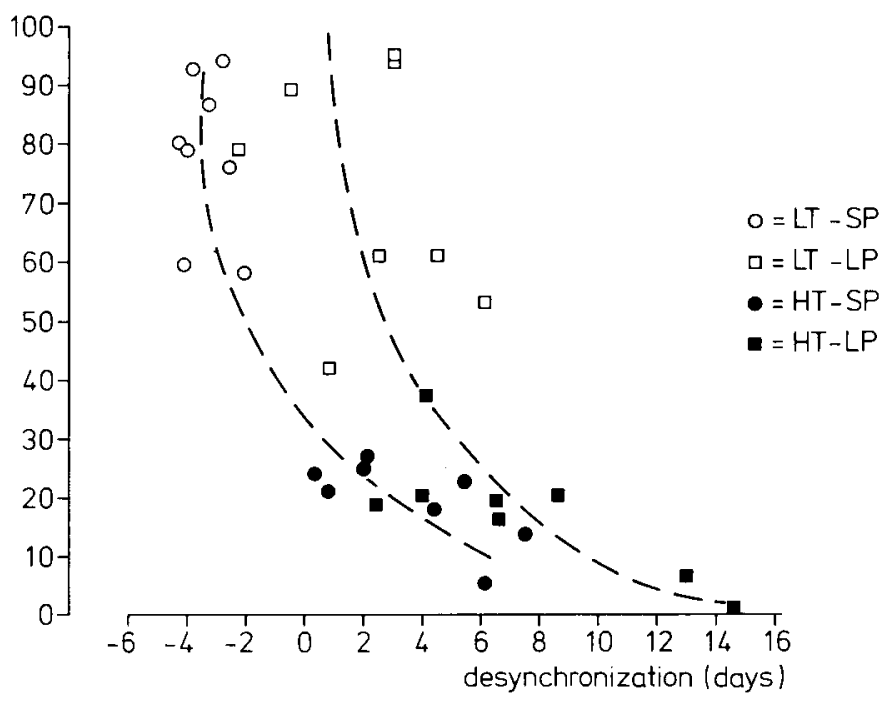

Fig. 4. The relationship between desynchronization and relative grain set of plants exposed to different climatic conditions.

Figs. 2, 3, 4 and 5 indicate that:

- female spikelet initiation was limited by short days at low temperature

- desynchronization explained much of the variation in number of female spikelets

- duration of the pollination period and desynchronization both explained much of the variation in relative grain set

- floret viability was reduced by drought and by high temperature

- desynchronization largely explained the variation in number of kernels. However, an increase in desynchronization effected by long days hardly reduced the number of kernels.

\section{Abnormalities in ear development}

In some treatments, abnormal development of the ear shoots was observed. These abnormalities were:

(1) silking before the ear shoot arose from the axil of the ear leaf. Ear shoots showing this usually had abnormally short shanks. This could lead to splitting of the sheath of the ear leaf

(2) poor development of the husks, so that the ears remained uncovered, sometimes for more than $60 \%$, and turned green

(3) restricted extrusion of silks from the envelope of husks because of poor silk 


$$
\begin{aligned}
& S P: y=-97.28 \ln (x+5)+284.49 ; r^{2}=0.828^{* * *}(n=16) \\
& L P: y=-253.73 \ln (x+5)+757.90 ; r^{2}=0.522^{* *}(n=16)
\end{aligned}
$$

number of kernels per uppermost ear

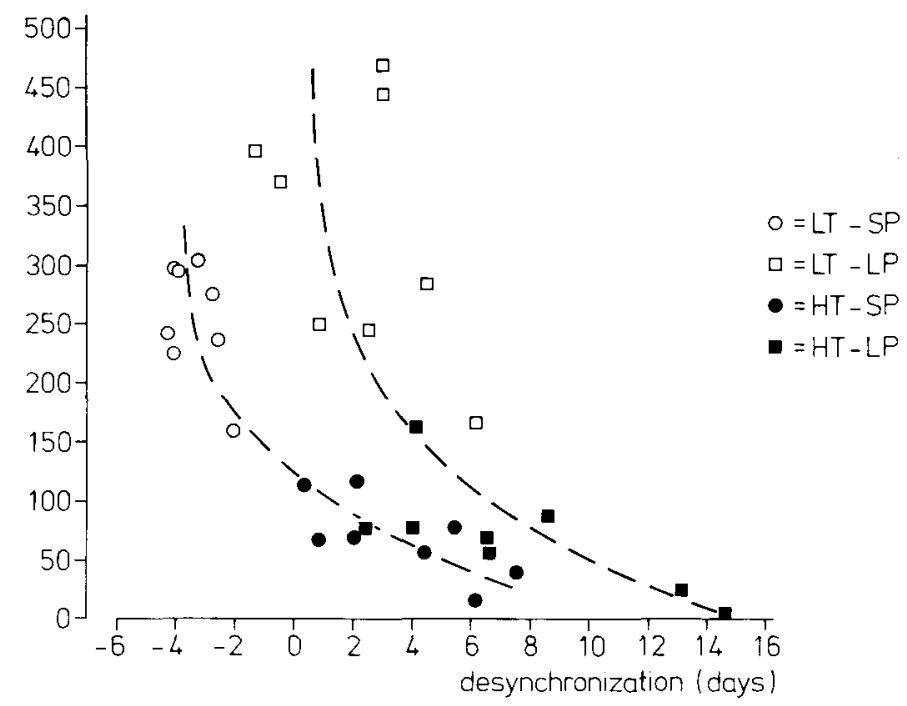

Fig. 5. The relationship between desynchronization and actual number of kernels of two hybrids grown under different climatic conditions.

elongation or because the husk envelope remained closed.

The first abnormality is not very important. It was more frequent at high temperature and drought but it did not affect the number of kernels set. The other two abnormalities are important because they both reduce the chances of successful kernel development. Poor development of the husks (abnormality 2) only occurred at high temperature. Other climatic factors did not affect its frequency. Also, restriction of extrusion of viable silks occurred almost exclusively at high temperature (especially with high noon temperature). However, the long-day treatment impeded the phenomenon.

Bastion showed many more abnormalities than LG 11 . This difference did not result in more kernels set for LG 11 .

\section{Leaf area}

The number of leaves was fairly constant. Yet total leaf area varied because the size of leaves varied according to treatment. This variation is relevant because assimilate supply may be a factor involved in kernel set and kernel abortion.

We observed that high temperature after tassel initiation caused a reduction in the area of leaves 6 and up $(1=$ lowest leaf $)$. Long photoperiod, however, caused an increase in the area of leaves 8 and up (LG 11), leaves 7 and up (Bastion, LT) or 
9 and up (Bastion, HT). Heat and water availability did not affect the leaves' final size consistently, but accelerated leaf senescence.

For the ear leaves, temperature and photoperiod treatments could result in differences of approximately $200 \mathrm{~cm}^{2}$ per leaf. For leaves above the uppermost ear, differences could even be $300 \mathrm{~cm}^{2}$ or more per leaf. These effects of temperature and photoperiod (especially the latter) on the leaf area could have contributed to the differences in number of kernels, because of their effects on assimilate supply before, during and after silking.

\section{Discussion}

Environmental factors have a great impact on the floral biology of maize. Not only the time of anthesis and silking are influenced by climatic factors; the balance between the tassel and the uppermost ear, the number of male and female florets, and the dynamics of their appearance, presence and functionality are also affected. This

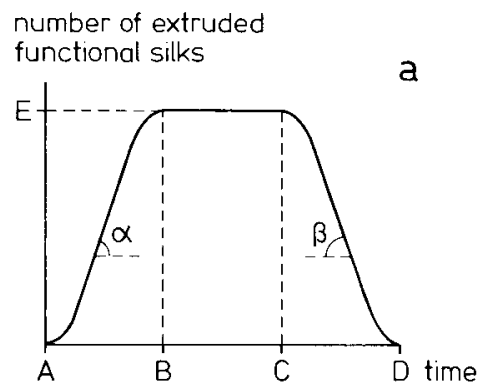

number of viable pollen grains shed per day

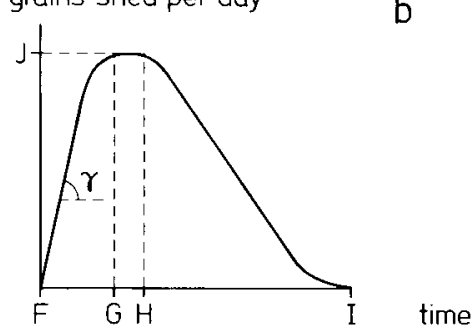

Fig. 6. Idealized representation of the dynamics of the extrusion and functionality of silks (a) and the dynamics of shedding, number and viability of pollen (b).

In Fig. $6 \mathrm{a} \mathrm{AB}$ gives the period of silk extrusion. $\mathrm{AD}$ is the total period over which functional silks are available. $C D$ is period of loss of functionality of female florets. E gives the maximum number of receptive silks. $\alpha$ indicates the number of silks extruding per day during $A B ; \beta$ indicates the rate of loss of receptiveness.

In Fig. $6 \mathrm{~b}$ FI gives the period of availability of viable pollen. FG gives the period over which the number of pollen grains shed per day is increasing. $\mathrm{GH}$ is the (short) period over which pollen production per day is maximum.

Note that the $y$-axis in Fig. $6 \mathrm{a}$ indicates total number, whereas the $y$-axis in Fig. $6 \mathrm{~b}$ gives number per day. 
is illustrated in the model shown in Fig. 6. Environmental factors proved to have an effect on the duration of $\mathrm{AB}$ and $\mathrm{FG}$ (e.g. availability of water), BC and $\mathrm{GH}$ (e.g. heat), AD and FI (e.g. temperature) and on the size of $E$ and $J$ (e.g. photoperiod), $\alpha$ (e.g. temperature), $\beta$ (e.g. availability of water) and $\gamma$ (e.g. temperature). Moreover, the ratios of $\mathrm{AD}$ to $\mathrm{FI}$ and of $\mathrm{AE}$ to $\mathrm{FJ}$ also depended on the climatic factors.

The duration of the pollination period (i.e. the duration of the period over which FI coincided with the time after A) proved to account for much of the variation in relative kernel set. The functionality of both pollen and female florets accounted for most of the remaining variability (cf. Sadras et al., 1985b). Desynchronization explained part of the variation in number of spikelets and thus probably also explained part of the variation in $\mathrm{AE}$. In this experiment $\mathrm{AD}, \mathrm{BC}, \mathrm{FG}, \mathrm{GH}$ and $\mathrm{HI}$ were not measured.

Loss of functionality of female florets (period CD) was probably never relevant in this experiment. On the other hand, abortion of fertilized florets was important.

If pollination by the plant's own tassel and pollination by pollen donor plants could have been possible on individual plants, the environmental effects on number of functional silks (Fig. 6a) and number of viable pollen grains per day (Fig. 6b) could have been distinguished. Moreover, in this experiment no use was made of the natural variation in pollen shedding and silking among plants. This variation is usually increased by environmental stress (see e.g. Struik, 1982).

This experiment under relatively low light intensity and low plant density clearly showed that number of kernels set is not merely a function of assimilate supply. The differences observed between low and high temperatures or between long and short days cannot be explained by differences in duration of photosynthesis per unit leaf area or by differences in leaf area itself. More research is needed to understand the floral biology of maize in order to be able to predict kernel yield in simulation models based on source-sink relationships.

\section{Acknowledgements}

We gratefully acknowledge the stimulation, helpful discussions and valuable criticism of Prof. Ir M. L. 't Hart, Dr Ir B. Deinum, Dr Ir O. Dolstra and Ir J. P. M. Bink.

\section{References}

Bertin, Ch., A. Panouillé \& S. Rautou, 1976. Obtention de variétés de maïs 'prolifiques en épis' productives en grain et à large adaptation écologique. Annales de l'Amélioration des Plantes 26: 387-418.

Buren, L. L., J. J. Mock \& I. C. Anderson, 1974. Morphological and physiological traits in maize associated with tolerance to high plant density. Crop Science 14: 426-429.

Dow, E. W., T. B. Daynard, J. F. Muldoon, D. J. Major \& G. W. Thurtell, 1984. Resistance to drought and density stress in Canadian and European maize (Zea mays L.) hybrids. Canadian Journal of Plant Science 64: 575-585.

Duncan, W. G., W. A. Williams \& R. S. Loomis, 1967. Tassels and the productivity of maize. Crop Science 7: 37-39. 
Fuchs, A., 1968. Beziehungen zwischen der Organogenese und der Ertragsbildung bei Zea mays. Zeitschrift für Pflanzenzüchtung 60: 260-283.

Hall, A. J., H. D. Ginzo, J. H. Lemcoff \& A. Soriano, 1980. Influence of drought during pollen-shedding on flowering, growth and yield in maize. Zeitschrift für Acker- und Pflanzenbau 149: 287-298.

Hall, A. J., F. Vilella, N. Trapani \& C. A. Chimenti, 1982. The effects of water stress and genotype on the dynamics of pollen-shedding and silking in maize. Field Crops Research 5: 349-363.

Herrero, M. P. \& R. R. Johnson, 1980. High temperature stress and pollen viability of maize. Crop Science 20: 796-800.

Herrero, M. P. \& R. R. Johnson, 1981. Drought stress and its effects on maize reproductive systems. Crop Science 21: 105-110.

Hollinger, S. E., 1981. Environmental effect on corn ear morphology, planting to silking. Dissertation Abstracts International B. 42 (5): 1700.

Kiniry, J. R. \& M. E. Keener, 1982. An enzyme kinetic equation to estimate maize development rates. Agronomy Journal 74: 115-119.

Montgomery, F. G., 1911. Correlation studies of corn. Nebraska Agricultural Experiment Station Annual Report 24: 108-159.

Moss, G. I. \& L. A. Downey, 1971. Influence of drought stress on female gametophyte development in corn (Zea mays L.) and subsequent grain yield. Crop Science 11: 368-372.

Muleba, N., T. G. Hart \& G. M. Paulsen, 1983. Physiological factors affecting maize (Zea mays L.) yields under tropical and temperate conditions. Tropical Agriculture (Trinidad) 60: 3-10.

Phillips, I. D. J., 1975. Apical dominance. Annual Review of Plant Physiology 26: 341-367.

Sadras, V. O., A. J. Hall \& T. M. Schlichter, 1985a. Kernel set of the uppermost ear in maize: I. Quantification of some aspects of floral biology. Maydica 30: 37-47.

Sadras, V. O., A. J. Hall \& T. M. Schlichter, 1985b. Kernel set of the uppermost ear in maize: II. A simulation model of effects of water stress. Maydica 30: 49-66.

Schoper, J. B., R. J. Lambert \& B. L. Vasilas, 1985. Influence of pollen, silk, and ear leaf status on maize seed set. Agronomy Abstracts, American Society of Agronomy, Madison, WI, p. 88.

Struik, P. C., 1982. Effect of a switch in photoperiod on the reproductive development of temperate hybrids of maize. Netherlands Journal of Agricultural Science 30: 69-83.

Struik, P. C., 1983a. The effects of switches in photoperiod on crop morphology, production pattern and quality of forage maize (Zea mays L.) under field conditions. Mededelingen Landbouwhogeschool Wageningen 83-2: 1-27.

Struik, P. C., 1983b. Effect of temperature on development, dry-matter production, dry-matter distribution and quality of forage maize (Zea mays L.). An analysis. Mededelingen Landbouwhogeschool Wageningen 83-3: 1-41.

Struik, P. C., 1983c. The effects of short and long shading, applied during different stages of growth, on the development, productivity and quality of forage maize (Zea mays L.). Netherlands Journal of Agricultural Science 31: 101-124.

Struik, P. C., 1983d. Physiology of forage maize (Zea mays L.) in relation to its production and quality. Doctoral thesis, Agricultural University, Wageningen, $252 \mathrm{pp}$.

Struik, P. C. \& B. Deinum, 1982. Effects of light intensity after flowering on the productivity and quality of silage maize. Netherlands Journal of Agricultural Science 30: 297-316.

Tollenaar, M. \& T. B. Daynard, 1978a. Kernel growth and development at two positions on the ear of maize (Zea mays). Canadian Journal of Plant Science 58: 189-197.

Tollenaar, M. \& T. B. Daynard, 1978b. Effect of defoliation on kernel development. Canadian Journal of Plant Science 58: 207-212. 